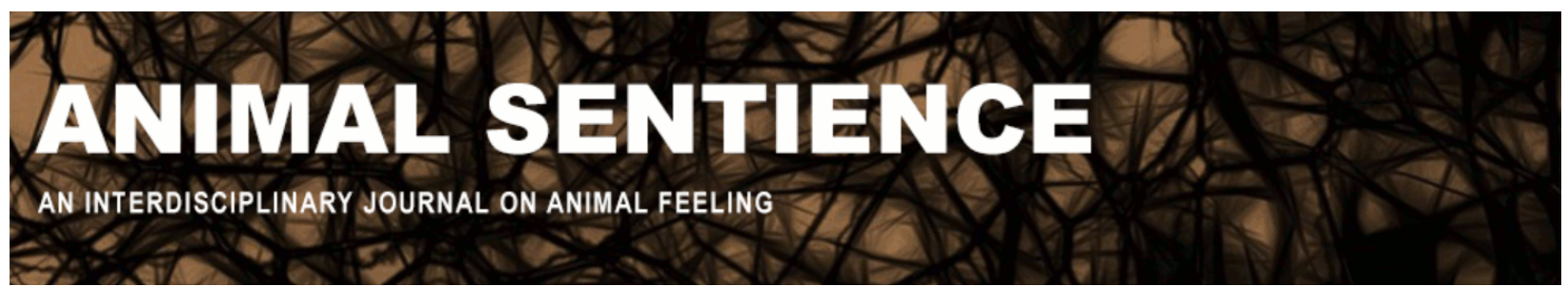

Sevillano, Verónica (2020) Group stereotypes: Human and nonhuman. Animal Sentience 27(15)

DOI: $10.51291 / 2377-7478.1549$

Date of submission: $2020-01-15$

Date of acceptance: 2020-01-25

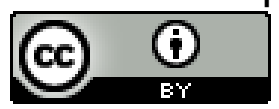

This article has appeared in the journal Animal

Sentience, a peer-reviewed journal on animal

cognition and feeling. It has been made open access,

free for all, by WellBeing International and deposited

in the WBI Studies Repository. For more information,

please contact

wbisr-info@wellbeingintl.org.

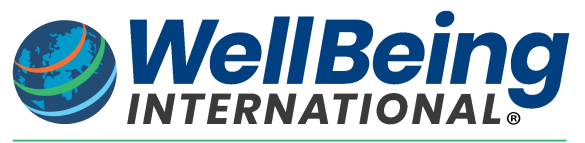

SOLUTIONS FOR PEOPLE, ANIMALS AND ENVIRONMENT 


\title{
Group stereotypes: Human and nonhuman
}

Commentary on Treves et al. on Just Preservation

\author{
Verónica Sevillano \\ Department of Social Psychology and Methodology \\ Autónoma University of Madrid, Spain
}

\begin{abstract}
Treves et al.'s target article emphasizes the importance of including nonhuman animals in the scope of conservation frameworks, countering an anthropocentric orientation in conservation biology. In support, I discuss how stereotypes of other animal species may bias our behavior toward them.
\end{abstract}

\begin{abstract}
Verónica Sevillano is an Assistant Professor of Social and Environmental Psychology at Autónoma University of Madrid, Spain. Her research examines empathy and cognitive biases in environmental concern, social stereotypes of animals, and human-animal relations. Website
\end{abstract}

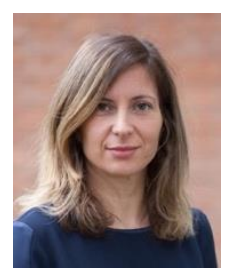

Treves et al. (2019) present a stimulating proposal for a nonanthropocentric approach to preservation. They stress the importance of considering animals as well as nature, youth and future generations in conservation biology. My commentary concerns the human dimension in conservation biology (also mentioned by Gupta 2019).

How humans understand animals. Treves et al. make a clear statement about considering animals as individuals instead of groups (i.e., species) as subjects of social justice issue concerns. Eliminating reference to species would provide more neutral decisions in situations of conflicting interests and would avoid biases driven by stereotypes. Social stereotypes are shared beliefs held by society about groups (human and nonhuman): In the social mind, for example, "immigrants" are seen as unintelligent and untrustworthy; "old people" as unskilled but well-intentioned; "wolves" as cruel, recreational killers, cunning, aggressive and bold (Johansson et al., 2012; Skogen, Mauz, \& Krange, 2008). Stereotypes are functional for human behaviors; they simplify decision-making and legitimize behaviors toward individuals, assuming the stereotyped features are shared across individuals and time.

Sevillano and Fiske (2019a) report that species stereotypes influence whether behaviors are perceived as right. For 25 animal species, we asked participants to rate to what extent they support a National Health Campaign for providing life-long care, including veterinary attention and medical and behavioral research, to improve the animals' lives. Species stereotypically perceived as friendly and intelligent such as dogs, horses and monkeys were favored over those stereotyped as unfriendly and unintelligent such rats, lizards and snakes. In another scenario, animals infected by viruses that cause suffering or hearing impairment could be treated with a vaccine (with limited availability) or nature could be left to take its course. Animals seen as 
incompetent (e.g., cows, lizards) were more likely to be passed over than those seen as competent (e.g., lions, dogs).

As with human groups, acknowledging stereotypes about nonhuman animals could help guide educational campaigns. Among the techniques available for combatting stereotypes in intergroup relations is personalization: providing personal information about individual members of the group (Brewer \& Miller, 1984). Treves et al.'s emphasis on individual animals shows convergent lines between conservation biology and social psychology (see also Sevillano \& Fiske, 2019b).

\section{References}

Brewer, M. B., \& Miller, N. (1984). Beyond the contact hypothesis: theoretical perspectives on desegregation. In N. Miller \& M. B. Brewer (Eds.), Groups in contact: the psychology of desegregation (pp. 281-302). Orlando, FL: Academic Press.

Gupta, R. (2019). Just preservation: From vision to reality. Animal Sentience 27(9).

Johansson, M., Karlsson, J., Pedersen, E., \& Flykt, A. (2012). Factors governing human fear of brown bear and wolf. Human Dimensions of Wildlife, 17, 58-74.

Sevillano, V., \& Fiske, S. T. (2019a). Stereotypes, emotions and behaviors associated with animals: a causal test of the stereotype content model and bias map. Group Processes \& Intergroup Relations, 22(6), 879-900 [Special Issue].

Sevillano, V., \& Fiske, S. T. (2019b). Animals as social groups: an intergroup relations analysis of human-animal conflicts. In K. Dhont \& G. Hodson (Eds.), Why people love and exploit animals: bridging insights from academia and advocacy (pp. 2542-2576). London: Routledge.

Skogen, K., Mauz, I., \& Krange, O. (2008). Cry wolf! Narratives of wolf recovery in France and Norway. Rural Sociology, 73, 105-133.

Treves, A., Santiago-Ávila, F., \& Lynn, W. (2019). Just preservation. Animal Sentience 27(1). 